\title{
A study on parental age, pregnancy events and autism spectrum disorders
}

\author{
Malla $\mathrm{A}^{1}$, Pathak $\mathrm{J}^{2}$, Shrestha $\mathrm{S}^{3}$, Pant $\mathrm{A}^{4}$, Shrivastava ${ }^{5}$, Amatya $\mathrm{M} \mathrm{S}^{6}$, Joshi $\mathrm{S} \mathrm{K}^{7}$
}

${ }^{1}$ Aakriti Malla, Lecturer, Department of Community Medicine, Kathmandu Medical College; ${ }^{2} J o h n$ Pathak, MBBS, Kathmandu Medical College; ${ }^{3}$ Sanjeev Shrestha, MBBS, Kathmandu Medical College; ${ }^{4}$ Aditi Pant, MBBS,Kathmandu Medical College; ${ }^{5}$ Trilok Shrivastava, MBBS, Kathmandu Medical College; ${ }^{6}$ Sunita Malekhu Amatya, Department of Anaesthesia, Bhaktapur Hospital, Chairperson Autism Care Nepal Society; ${ }^{7}$ Sunil Kumar Joshi, Head of Department of Community Medicine, Kathmandu Medical College, Kathmandu, Nepal

\begin{abstract}
Background: Autism spectrum disorder (ASD) is a neurological disorder which usually appears before the age of 3 . Several genetic or environmental factors may be involved in onset of Autism Spectrum Disorder.

Objectives: To find relationship of Autism Spectrum Disorder with different maternal factors and events during pregnancy.

Methodology: This is a retrospective case control study with total of 104 children of age 3-15 years as a sample, 52 were cases and 52 were controls. The study unit was selected from the database of Autism Care Nepal (ACN) for cases and questionnaire was designed based on the probable risk factors of Autism Spectrum Disorder from existing literature. Controls were chosen from schools, questionnaire being filled by asking questions to the mothers of the child with same age group as the cases, similar socio-economic background and intellectually normal.

Results: There were $78.8 \%$ males and $21.1 \%$ females among cases and $53.8 \%$ were male and $46.1 \%$ were female among controls which show male predominance among cases. Among various maternal risk factors, the maternal second hand smoking (P value: 0.04 ) and maternal respiratory tract infection (P value: 0.04 ) were found to be statistically significant. Regarding neonatal factors, birth asphyxia ( $P$ value: 0.003$)$, delayed cry (P value: 0.000$)$ and neonatal jaundice ( $P$ value: 0.05) were found to be statistically significant.

Conclusion: We found association of maternal second hand smoking, respiratory tract infection and among neonatal factors, birth asphyxia, delayed cry and neonatal jaundice to be associated with Autism Spectrum Disorder.
\end{abstract}

Key words: Autism, Autistic Disorder, Maternal age, Pregnancy

A utism spectrum disorder (ASD) is a group of neurodevelopmental disorder defined by social and communication deficits and repetitive behaviors that are typically detectable in early childhood, continuing throughout life. Onset of unusual behavior often occurs in infancy or second year of life and symptoms of autism usually manifest by the age of three years ${ }^{1}$. It is characterized by impaired social interaction, problems with verbal and nonverbal communication, and unusual, repetitive, or severely limited activities and interests ${ }^{2}$.

Autism is a growing challenge worldwide. According to Centers for Disease Control and Prevention (CDC) - recent

Address for correspondence

Dr. Aakriti Malla

Lecturer, Department of Community Medicine,

Kathmandu Medical College study from 11 Autism and Developmental Disabilities Monitoring (ADDM) network sites, 14.6 per 1,000 (1 in 68) children aged eight years in the United States have been identified as having an Autism Spectrum Disorder $(\mathrm{ASD})^{3}$, indicating a rise in the past two decades. But this may not be the true picture as the prevalence estimates from Asian countries like China (0.003-0.17\%), Japan (0.011-0.21\%) and South Korea (2.64\%) vary widely across time and country ${ }^{4}$. Based on the studies in Asian countries, nearly 1.7-2 million individuals are estimated to be affected by ASD in India 5 . Although developed countries have achieved much in autism research and determining its prevalence and etiology, it still remains a new topic for countries like Nepal. It poses a much greater and serious challenge in countries like Nepal, because of the severity of the impact on the affected individuals and their families, along with economic burden and lack of scientific studies. 
Etiology of autism is still unknown, it is understood for only a small percentage of cases, and little is known about how or when etiologic factors act. Twin and family studies have indicated the importance of genetic factors in Autism disorders, but environmental factors also appear to play a role ${ }^{6}$. Many studies have been conducted throughout the world so as to find evidence between associations of parental age, prenatal, perinatal and neo-natal risk factors with ASD. However, the results from these studies are quite inconsistent; after adjusting for other potential confounders, some reported the role of advanced paternal age only ${ }^{7,8}$, another group reported the role of advanced maternal age only ${ }^{6}$, and some others point to advanced age of both parents ${ }^{9-12}$.

There was association found between advanced maternal age (OR: 1.80 [95\% of $\mathrm{Cl}: 1.27,2.24], \mathrm{p}=0.0008)$ and ASD, among 471 cases 323 (68.5\%) fathers were 30 years and above ${ }^{13}$. Offspring of women $>=35$ years of age were more likely (OR: 1.68 [95\% Cl: $1.01-2.78], p=0.43$ ) to have ASD compared with offspring of women 20 to 34 years of age. Prenatal factors most common among children with ASD were advanced maternal age and parity, perinatal factors were breech presentation and primary caesarean delivery and there were no significant associations with neonatal factors ${ }^{14}$.

The meta-analysis found few statistically significant risk factors. Maternal gestational diabetes was associated with a two-fold increased risk of autism. In addition, a significant $81 \%$ elevated risk was observed in relation to maternal bleeding during pregnancy. Maternal medication use was also associated with a $46 \%$ increased risk. Maternal age at birth over 30 was associated with an increased risk with effect estimates ranging from a $27 \%$ increased risk (30-34 vs. $25-29$ ) to a $106 \%$ increase in risk $(40+$ vs. $<30)$. Thirteen studies were included in the meta-analysis of maternal age at birth. The trend test included nine studies and indicated a significant increase in risk of autism with increasing maternal age at birth ( $p$-value test for trend=0.02). Increased paternal age at birth was also found to be a significant risk factor ( $p$-value test for trend=0.004), with a five-year increase in paternal age associated with a $3.6 \%$ increase in risk. Individual exposure category effect estimates ranged from $1.24(30-39$ vs. $<30)$ to $1.44(40+\text { vs. } 25-29)^{15}$.

There has not been much scientific study on autism in Nepal. To our knowledge there has not been any study to characterize parental age, pre-natal, peri-natal, and neonatal risk factors and assess their association with ASD in Nepalese population. Autism Care Nepal, only active organization working on this field in Nepal roughly estimates 50000 people to be affected with this disorder but till date only 196 children have received service in this center out of which majority are with developmental disorders and only 84 are diagnosed with autism.

\section{METHODOLOGY}

This is a case control study with the main objective to assess various risk factors for Autism Spectrum Diseases (ASD).The children included in the sample were evaluated in Autism Care Nepal where they were assessed and diagnosed with an ASD. Since there are no diagnostic centers here in Nepal, all the reports of the patients were sent to India for confirmation of the clinical diagnosis. Internationally accepted classification systems such as Diagnostic and Statistical Manual of Mental Disorders IV (DSM IV) and International Classification of Diseases 10 (ICD 10) ${ }^{16}$ have been used along with Indian Scale for Assessment of ASD(ISAA)for the diagnosis and certification.

The study unit was selected from the database of Autism Care Nepal (ACN), a center dealing with children with ASD for cases and a questionnaire was designed based on the probable risk factors of ASD from existing literature and those likely as per expert's advice. Controls were chosen from schools, questionnaire being filled by asking questions to the mothers of the child with same age group as the cases, similar socio economic background and intellectually normal. The sample size was established on the basis of required levels of statistical power to meet the primary study objectives.

The targeted populations were children aged 3 to 15 from all over the country who were identified to as having Autism Spectrum Disorder by Autism Care Nepal according to International Classification of Diseases 10 (ICD10) and Diagnostic and Statistical manual of mental disorders IV (DSM IV).

Out of the registered total of 196 children in ACN, 112 were found to be patients of developmental disorders, of the remaining 84 with the confirmed diagnosis, parents of 32 children refused for the consent of the study and hence 52 children's parents were questioned. The study comprises of 41 boys and 11 girls. Each child was matched with controls ( 28 boys and 24 girls) within the same age group as cases ( 3 to 15 years age group) and the similar socio economic background, from different schools with intellectually normal children of the country. The case to control ratio is 1:1. 
Study duration was total of 3 months. Cases and controls were surveyed after informed written consent through a questionnaire that included history as stated by their parents and retrospective report mostly regarding the parental age at birth of the child, pregnancy events (antenatal, natal and post natal).

For statistical analysis, parametric and non-parametric tests were applied to observe association between various variables.

SPSS (Statistical Package for Social Sciences) Version 20 was used as a statistical software.

\section{RESULTS}

A total of 104 participants (52 cases and 52 controls) were included in the study with the age group 3 to 12 years with the mean age of 7.04 in cases and 7.29 in controls. Whereas $78.8 \%$ were male and $21.1 \%$ female among cases and $53.8 \%$ were male and $46.1 \%$ were female among controls.

\section{PARENTAL FACTORS}

Various parental factors were evaluated which showed the majority of mother's age among cases were 21-25 years $(42.3 \%)$ and among controls were $26-30$ years (42.3\%) (Figure 1), similarly father's age among cases and controls both were $31-35$ years $(36.5 \%$ and $34.6 \%$ respectively). (Figure 2)
Regarding the occupation of the parents, most of the mothers were housewives among cases as well as controls ( $76.9 \%$ and $46.3 \%$ respectively) whereas most of the father's occupation among cases and controls were employees (51.9\% and 50\% respectively).

\section{NATAL FACTORS}

Different maternal characteristics during gestation were analyzed with their association with Autism. Out of them, maternal second hand smoking were more among cases $(26.9 \%$ in cases and $5.8 \%$ in controls, OR $6.08,95 \% \mathrm{Cl}-1.6-22.4, \mathrm{P}$ value=0.04) was found to be significant. (Table 1)

Similarly regarding maternal infections, respiratory infection during pregnancy was $7.7 \%$ among mothers of cases and none of the mothers of control with OR 2.08, $95 \% \mathrm{Cl}-1.6-2.5, \mathrm{P}$ value $=0.04$ was found to be significant. Other factors like gestational diabetes, hypertension, hyperemesis, and premature rupture of membrane, trauma or breech presentation did not show significant association with autism.

\section{NEONATAL FACTORS}

Six different neonatal characteristics were analyzed for its association with autism. Out of which birth asphyxia was present in $15.4 \%$ of cases and none of the controls with OR 2.1, 95\% Cl-1.7-2.7, $\mathrm{P}$ value $=0.003$ which was significant. Also, delayed cry was found among $26.9 \%$ of cases and none of the controls with OR $2.3,95 \% \mathrm{Cl}-1.8$ $3.0, P$ value $=0.000$ was found to be significant.

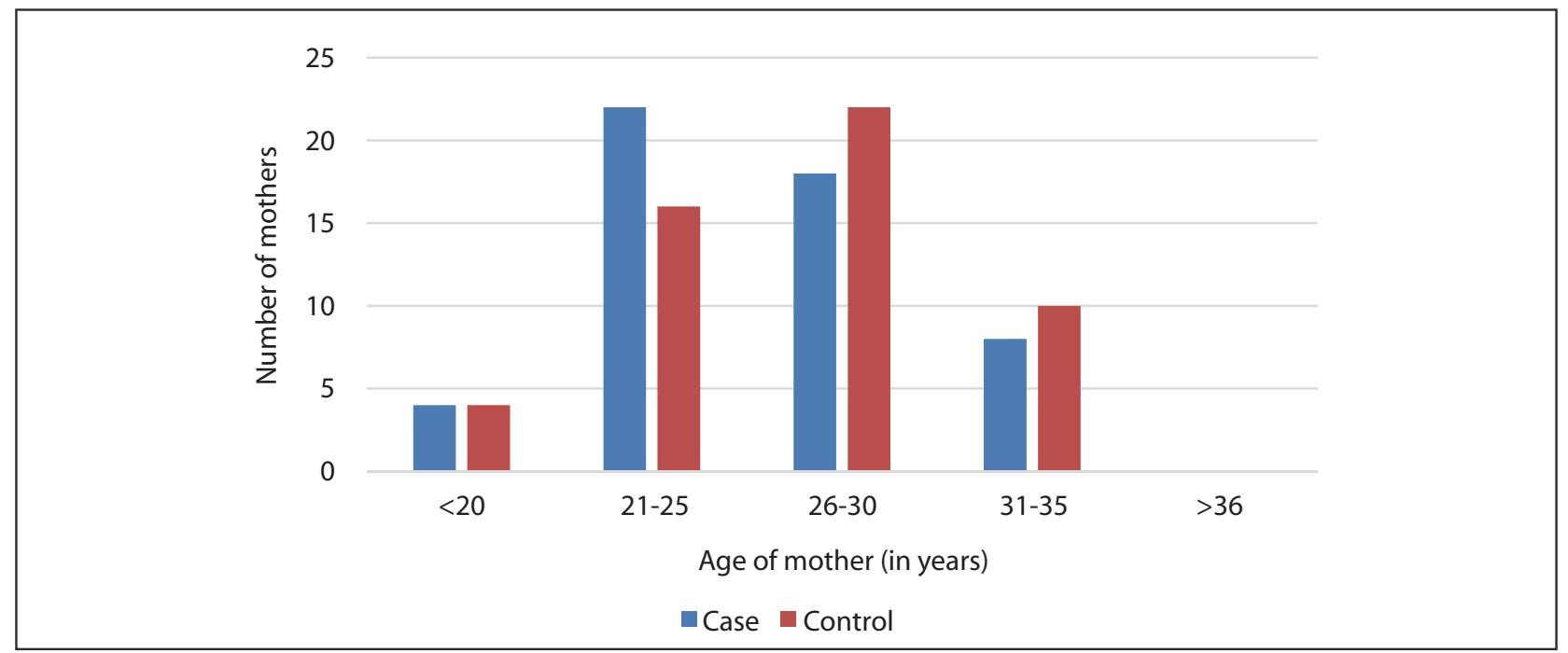

Figure 1: Relation of mother's age with case and controls 


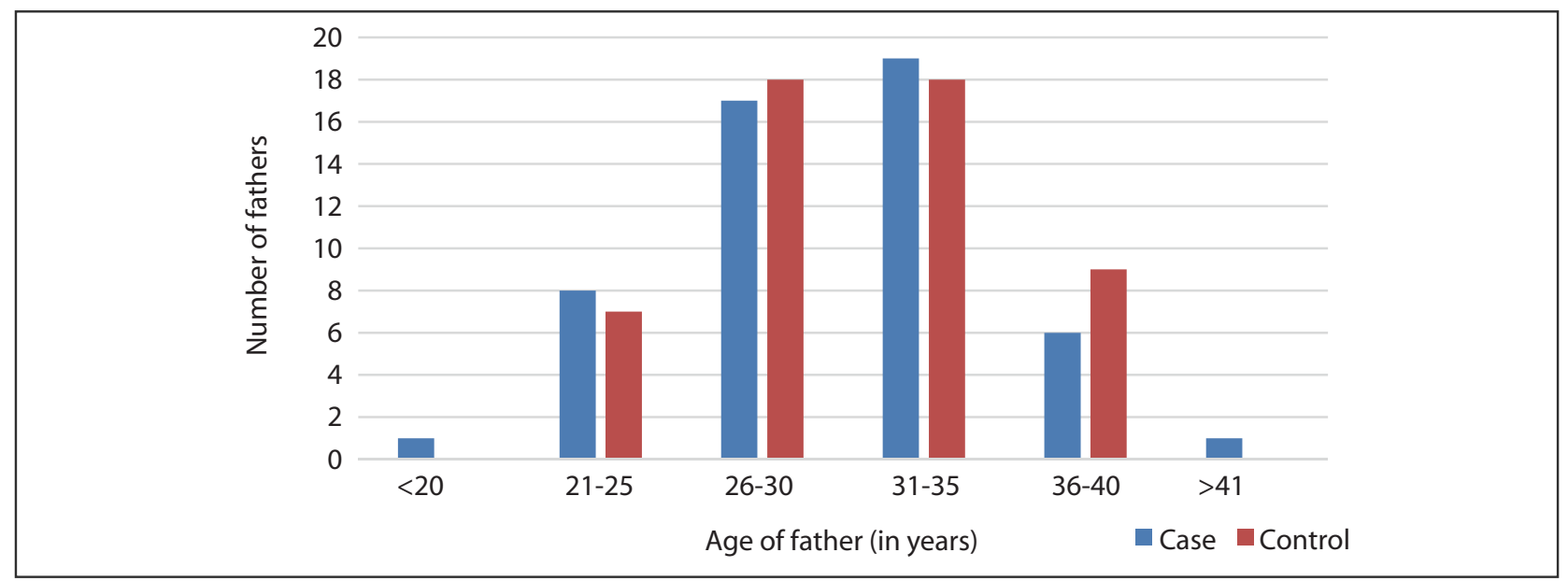

Figure 2: Relation of father's age with case and controls

\section{DISCUSSION}

The main objective of our study is to find any association of ASD with various parental and neonatal characteristics.

\section{Socio-demographic comparison between cases and controls:}

41 (78.8\%) boys and 11 (53.8\%) girls cases whereas $28(21.2 \%)$ boys and $24(46.2 \%)$ girls controls were included in our study. The mean age of the cases and control were $7.04+/-2.5$ and $7.29+/-2.2$ respectively.

In various studies conducted worldwide there has been associations of maternal age with ASD. Maternal age > 34 years had significant association with ASD (OR:1.676, 95\% Cl:1.01-2.71, P value: 0.0432$)^{14}$

The highest maternal age at the time of pregnancy were ranging from 21-25 years (42.3\%) and 26-30 years $(42.3 \%)$ in cases and control respectively. Only $7.7 \%$ were less than 20 years in both cases and control. Maximum father's age range was $31-35$ years (36.5\%) in cases. In control group both 26-30 and 31-35 years age range had highest and equal prevalance (34.6\%). The least age being less than 20 years and highest more than 40 years in both cases and control. Advanced maternal and paternal age (>34 years) wasn't significant in our study as compared to above study. The small number of population under study may be the cause of such results.

Mother's occupation showed that both cases and control group, most of the mothers were housewives $(76.9 \%$ and $46.3 \%$ respectively). In cases, self employed mothers were the least (1.9\%) and in controls health professionals were the minimum (7.7\%).

Most of the fathers were employee (51.9\% and 50\%), and least were unemployed(1.9\% and $0 \%)$.
In a study done by Piven J, et al. showed that parents of the autistic probands had significantly higher rates of major depressive disorder and social phobia ${ }^{17}$. In our study all of the participants (both cases and controls) denied of having any psychiatric illness in their family, hence the relation of psychiatric illness in the family with ASD couldn't be established.

\section{Mother's health related factors distribution between cases and controls}

We tried to see if the hypothesis of maternal conditions during pregnancy was associated with ASD as done in previous studies $^{1,18}$.

Maternal smoking during pregnancy was not significant, as neither of the cases nor did the controls have history of first hand smoking during pregnancy. This may be due to stigmas that the interviewee doesn't want to disclose her smoking habits or may be due to the fact that health education regarding injurious effect of smoking to pregnant mothers have been circulating in the country for some time now. However, in our study maternal second hand smoking during pregnancy has been significantly associated with development of ASD in the child $\left(\mathrm{OR}_{\mathrm{adj}} 6.08,95 \% \mathrm{Cl}: 1.6-22.4, \mathrm{P}\right.$ value: 0.04$)$. Similar results were also seen in study conducted in China $\left(\mathrm{OR}_{\mathrm{adj}} \text { : } 3.53,95 \% \mathrm{Cl} \text { : 1.30-9.56, P value: } 0.01\right)^{1}$.

Maternal habits of alcohol consumption during pregnancy were seen in $5.8 \%$ of the cases and $3.8 \%$ of the controls. (P value: 0.64 ). Similarly, gestational diabetes in mother were seen in $5.8 \%$ of the cases and none in control group in our study. But both failed to show any association. 
Table 1: Natal factors and its association with ASD

\begin{tabular}{|c|c|c|c|c|}
\hline & $\begin{array}{c}\text { Cases } \\
\text { Frequency (Percentage) }\end{array}$ & $\begin{array}{c}\text { Controls } \\
\text { Frequency (Percentage) }\end{array}$ & P value & $\begin{array}{l}\text { Odds Ratio (95\% } \\
\text { Cl) }\end{array}$ \\
\hline \multicolumn{5}{|c|}{ Diseases not associated with pregnancy: } \\
\hline $\begin{array}{l}\text { Yes } \\
\text { No }\end{array}$ & $\begin{array}{c}5(9.6 \%) \\
47(90.6 \%)\end{array}$ & $\begin{array}{c}6(11.5 \%) \\
(88.5 \%)\end{array}$ & 0.75 & $0.816(0.23-2.8)$ \\
\hline \multicolumn{5}{|c|}{ Maternal Smoking: } \\
\hline $\begin{array}{l}\text { Yes } \\
\text { No }\end{array}$ & $\begin{array}{c}0 \\
52(100 \%)\end{array}$ & $\begin{array}{c}0 \\
52(100 \%)\end{array}$ & & \\
\hline \multicolumn{5}{|l|}{ Maternal Alcohol: } \\
\hline $\begin{array}{l}\text { Yes } \\
\text { No }\end{array}$ & $\begin{array}{c}3(5.8 \%) \\
49(94.2 \%)\end{array}$ & $\begin{array}{c}2(3.8 \%) \\
50(96.2 \%)\end{array}$ & 0.64 & $1.5(0.24-9.5)$ \\
\hline \multicolumn{5}{|c|}{ Maternal second hand smoking: } \\
\hline $\begin{array}{l}\text { Yes } \\
\text { No }\end{array}$ & $\begin{array}{l}14(26.9 \%) \\
38(73.1 \%)\end{array}$ & $\begin{array}{c}3(5.8 \%) \\
49(94.2 \%)\end{array}$ & 0.04 & $6.08(1.6-22.4)$ \\
\hline \multicolumn{5}{|c|}{ Gestational Diabetes: } \\
\hline $\begin{array}{l}\text { Yes } \\
\text { No }\end{array}$ & $\begin{array}{c}3(5.8 \%) \\
49(94.2 \%)\end{array}$ & $\begin{array}{c}0 \\
52(100 \%)\end{array}$ & 0.79 & $2.061(1.6-2.5)$ \\
\hline \multicolumn{5}{|c|}{ Gestational High BP: } \\
\hline $\begin{array}{l}\text { Yes } \\
\text { No }\end{array}$ & $\begin{array}{c}1(1.9 \%) \\
51(98.1 \%)\end{array}$ & $\begin{array}{c}1(1.9 \%) \\
51(98.1 \%)\end{array}$ & 1.00 & $1.0(0.61-16.42)$ \\
\hline \multicolumn{5}{|l|}{ UTI } \\
\hline $\begin{array}{l}\text { Yes } \\
\text { No }\end{array}$ & $\begin{array}{c}2(3.8 \%) \\
50(96.2 \%)\end{array}$ & $\begin{array}{c}1(1.9 \%) \\
51(98.1 \%)\end{array}$ & 0.55 & $2.0(0.17-23.2)$ \\
\hline \multicolumn{5}{|c|}{ Respiratory Infection: } \\
\hline $\begin{array}{l}\text { Yes } \\
\text { No }\end{array}$ & $\begin{array}{c}4(7.7 \%) \\
48(32.3 \%)\end{array}$ & $\begin{array}{c}0 \\
52(100 \%)\end{array}$ & 0.04 & $2.08(1.6-2.5)$ \\
\hline \multicolumn{5}{|c|}{ Gestational Bleeding: } \\
\hline $\begin{array}{l}\text { Yes } \\
\text { No }\end{array}$ & $\begin{array}{c}3(5.8 \%) \\
49(94.2 \%)\end{array}$ & $\begin{array}{c}1(1.9 \%) \\
51(98.1 \%)\end{array}$ & 0.3 & $3.1(0.31-31.0)$ \\
\hline \multicolumn{5}{|l|}{ Edema: } \\
\hline $\begin{array}{l}\text { Yes } \\
\text { No }\end{array}$ & $\begin{array}{c}9(17.3 \%) \\
43(82.7 \%)\end{array}$ & $\begin{array}{c}3(5.8 \%) \\
49(94.2 \%)\end{array}$ & 0.06 & $3.41(0.86-13.4)$ \\
\hline \multicolumn{5}{|c|}{ Severe Hyperemesis } \\
\hline $\begin{array}{l}\text { Yes } \\
\text { No }\end{array}$ & $\begin{array}{c}6(11.5 \%) \\
46(88.5 \%)\end{array}$ & $\begin{array}{c}5(45.5 \%) \\
47(90.4 \%)\end{array}$ & 0.75 & $1.22(0.35-4.2)$ \\
\hline PROM & & & & \\
\hline $\begin{array}{l}\text { Yes } \\
\text { No }\end{array}$ & $\begin{array}{c}4(7.7 \%) \\
48(92.3 \%)\end{array}$ & $\begin{array}{c}3(5.8 \%) \\
49(94.2 \%)\end{array}$ & 0.69 & $1.3(0.28-6.40)$ \\
\hline Trauma during $\mathrm{p}$ & & & & \\
\hline $\begin{array}{l}\text { Yes } \\
\text { No }\end{array}$ & $\begin{array}{c}3(5.8 \%) \\
49(94.2 \%)\end{array}$ & $\begin{array}{c}0 \\
52(100 \%)\end{array}$ & 0.07 & $2.06(1.68-2.52)$ \\
\hline Breech presenta & & & & \\
\hline $\begin{array}{l}\text { Yes } \\
\text { No }\end{array}$ & $\begin{array}{c}4(7.7 \%) \\
48(92.3 \%)\end{array}$ & $\begin{array}{c}3(5.8 \%) \\
49(94.2 \%)\end{array}$ & 0.69 & $1.3(2.8-6.4)$ \\
\hline Nuchal cord & & & & \\
\hline $\begin{array}{l}\text { Yes } \\
\text { No }\end{array}$ & $\begin{array}{c}2(3.8 \%) \\
50(96.2 \%)\end{array}$ & $\begin{array}{c}2(3.8 \%) \\
50(96.2 \%)\end{array}$ & 1.0 & $1.0(0.1-7.3)$ \\
\hline Trauma during $\mathrm{d}$ & & & & \\
\hline $\begin{array}{l}\text { Yes } \\
\text { No }\end{array}$ & $\begin{array}{c}2(3.8 \%) \\
50(96.2 \%)\end{array}$ & $\begin{array}{c}1(1.9 \%) \\
51(98.1 \%)\end{array}$ & 0.55 & $2.0(0.1-23.2)$ \\
\hline Delivery Type & & & & \\
\hline $\begin{array}{l}\text { Normal Delivery } \\
\text { CS }\end{array}$ & $\begin{array}{l}28(53.8 \%) \\
24(46.2 \%)\end{array}$ & $\begin{array}{l}37(71.2 \%) \\
15(28.8 \%)\end{array}$ & 0.06 & $0.47(0.21-1.0)$ \\
\hline
\end{tabular}


Table 2: Neonatal Characteristics during delivery and association with ASD

\begin{tabular}{|c|c|c|c|c|}
\hline & $\begin{array}{c}\text { Cases } \\
\text { Frequency(Percentage) }\end{array}$ & $\begin{array}{c}\text { Controls } \\
\text { Frequency(Percentage) }\end{array}$ & P value & $\begin{array}{c}\text { Odds Ratio } \\
(95 \% \mathrm{CI})\end{array}$ \\
\hline \multicolumn{5}{|c|}{ Birth Asphyxia: } \\
\hline Yes & $8(15.4 \%)$ & 0 & \multirow{2}{*}{0.003} & \multirow{2}{*}{$2.1(1.7-2.7)$} \\
\hline No & $44(84.6 \%)$ & $52(100 \%)$ & & \\
\hline \multicolumn{5}{|c|}{ Delayed Cry: } \\
\hline Yes & $14(26.9 \%)$ & 0 & \multirow{2}{*}{0.000} & \multirow{2}{*}{$2.3(1.8-3.0)$} \\
\hline No & $38(73.1 \%)$ & $52(100 \%)$ & & \\
\hline \multicolumn{5}{|c|}{ Neonatal Jaundice: } \\
\hline Yes & $11(21.2 \%)$ & $4(7.7 \%)$ & \multirow{2}{*}{0.05} & \multirow{2}{*}{$3.2(0.9-10.8$} \\
\hline No & $41(78.8 \%)$ & $48(92.3 \%)$ & & \\
\hline \multicolumn{5}{|c|}{ Eczema immediately after birth: } \\
\hline Yes & $1(1.9 \%)$ & $1(1.9 \%)$ & \multirow{2}{*}{1.00} & \multirow{2}{*}{$1(0,06-16.4)$} \\
\hline No & $51(98.1 \%)$ & $51(98.1 \%)$ & & \\
\hline \multicolumn{5}{|c|}{ Seizure immediately after birth: } \\
\hline Yes & $1(1.9 \%)$ & 0 & 1.00 & \multirow{2}{*}{$2.0(1.6-2.4)$} \\
\hline No & $51(98.1 \%)$ & $52(100 \%)$ & & \\
\hline
\end{tabular}

However gestational high blood pressure and preeclampsia (new onset of hypertension after 20 weeks of gestation with edema) have been associated with ASD in the past studies $\left(\mathrm{OR}_{\text {adj: }}: 2.35,95 \% \mathrm{Cl}\right.$ : 1.04-5.30, $\mathrm{P}$ value: 0.04$)^{1}$. The reason being poor placental perfusion and function, which may result in damage to fetal development through hypoxia. In contrast to this, an autism based meta-analysis ${ }^{15}$ did not find confirmation for an association with autism. Likewise a large Swedish study ${ }^{19}$ showed $\mathrm{OR}_{\text {adj }}$ of 1.6 for pre-eclampsia which was not significant.

Our study $\left(\mathrm{OR}_{\mathrm{adj}}:\right.$ 1.0, 95\% Cl: 0.61-16.42, P value: 1.00$)$ was of insufficient capacity to evaluate preeclampsia and hypertension, as these were rare in both case (1.9\%) and control (1.9\%) groups.

Other gestational complications like infections such as UTI seem not to be associated with ASD. $\left(O_{\text {adj }}: 2.0,95 \%\right.$ Cl: 0.17-23.2, $\mathrm{P}$ value: 0.55 )

However respiratory illness during pregnancy shows an association $\left(\mathrm{OR}_{\mathrm{adj}}\right.$ : $\left.2.08[95 \% \mathrm{Cl}] \mathrm{P}=0.04\right)$. Research has also shown that environmental factors, such as viruses, may also play a role in autism. Maternal influenza infection was associated with a two fold increased risk of infantile autism and prolonged episodes of fever caused a threefold increased risk of infantile autism was seen as potential risk factors for ASD/infantile autism in a study done in Denmark ${ }^{20}$. Similarly, in another study no overall association between diagnoses of any maternal infection during pregnancy and ASD was observed [adjusted odds ratio $\left(\mathrm{OR}_{\mathrm{adj}}\right)=1.15,95 \%$ confidence interval $(\mathrm{Cl})$
0.92-1.43]. However, women with infections diagnosed during a hospital admission $\left(\mathrm{OR}_{\mathrm{adj}}=1.48,95 \% \mathrm{Cl} 1.07-\right.$ 2.04), particularly bacterial infections $\left(\mathrm{OR}_{\mathrm{adj}}=1.58,95 \%\right.$ $\mathrm{Cl}$ 1.06-2.37), were at increased risk of delivering a child with ASD. Multiple infections during pregnancy were associated with ASD $\left(\mathrm{OR}_{\mathrm{adj}}=1.36,95 \% \mathrm{Cl} 1.05-1.78\right)^{21}$.

The mechanism, by which viral infection may lead to autism, be it through direct infection of the central nervous system (CNS), through infection elsewhere in the body acting as a trigger for disease in the CNS, through alteration of the immune response of the mother or offspring, or through a combination of these, is not yet known ${ }^{22}$.

Maternal edema during pregnancy is a common phenomenon and it was found in cases in $17.3 \%$ and $5.8 \%$ in controls. For maternal edema, a similar study by Zhang X., et al. were able to conduct adjusted analysis, and it became a significant risk factor for autism after adjusting for paternal age at delivery, gender and birth year ${ }^{1}$.

\section{Birth events and Newborn Conditions comparison between cases and controls}

In our study, children with ASD born through Normal Delivery were found to be $53.8 \%$ compared to children born by Caesarean section with $46.2 \%$, whereas in controls, normal deliveries were $71.2 \%$ and Caesarean section was 28.8\% (adjusted OR: 0.47 [95\% Cl: 0.21-1.0] $\mathrm{P}=.006)$. In a similar study, children with an ASD were more likely to be born by primary cesarean delivery (adjusted OR: 1.67 [95\% Cl: 1.03-2.73] $P=.039)^{14}$. 
Similarly, an Australian (Glasson et al. 2004) and a Swedish study (Hultman et al. 2002) both reported cesarean sections to be associated with increased autism risk $^{18,23}$.

Cesarean delivery showed a borderline association in both the unadjusted and the adjusted analysis $\left(\mathrm{OR}_{\mathrm{adj}}=\right.$ $1.83, \mathrm{p}$ value $=0.06)^{1}$.

Similarly ASD association with breech presentation was found to be just $7.7 \%$ in cases and $5.8 \%$ in controls (OR: 1.3 [95\% Cl: 2.8-6.4] P=0.69) compared to other studies where ASD with breech presentation (adjusted OR: 2.10 [95\% Cl: 1.11-3.98] $\mathrm{P}=.023)$. This study suggests a small role for prenatal, perinatal, and neonatal risk factors in the ASD population overall.

Taken separately, risk factors found in this study (maternal age, parity, breech presentation) are difficult to explain ${ }^{14}$.

Premature rupture of membrane was $7.7 \%$ among cases and 5.8\% in controls (OR: 1.3 [95\% Cl: 0.28-6.4] P=0.69). Similarly, in a study by Zhang $X$. et al., there was an association of $13.7 \%$ cases \& $2.1 \%$ control (OR: 7.37 [Cl: 1.62-33.64] $\mathrm{P}=0.005)^{1}$.

Association of negative perinatal factors and birth asphyxia with ASD was $15.4 \%$ among cases and $0 \%$ in controls (OR: 2.1 [95\% Cl : 1.7-2.7] $\mathrm{P}=0.003$ ), this shows a relation between birth asphyxia and ASD. Similarly, delayed cry with ASD was found to have a very strong relation with $26.9 \%$ among cases and $0 \%$ in controls (OR 2.3 [95\% Cl : 1.8-3.0] P = 0.000). In a similar study done, Neonatal Factors, Birth weight, congenital anomalies, assisted ventilation for $=30$ minutes, and 5-minute Apgar scores were also not associated with increased risk of $\mathrm{ASDs}^{14}$.

ASD with nuchal cord was seen in $3.8 \%$ of the cases and 3.8\% of controls (OR: 1 [95\% Cl: 0.1-7.3] P=1.0) and ASD with trauma during delivery was seen in $3.8 \%$ in cases and $1.9 \%$ in controls (OR: 2.0 [95\% Cl: 0.1-23.2] $\mathrm{P}=0.55)$. Similar findings from Prenatal and Perinatal Risk Factors for Autism in China, that nuchal cord occurred significantly more frequent among children with autism $(23.2 \%)$ than among the controls $(6.3 \%)$ has not been previously reported in literature'.

Fetal hypoxia may form a relationship between gestational bleeding and autism. Maternal bleeding is a complication that is believed to be associated with fetal hypoxia.
Fetal distress, maternal hypertension, prolonged labor, cord complications, low Apgar score, and Cesarean delivery are other pregnancy-related factors that are believed to be related to hypoxia and have been associated with autism risk in some, but not all, studies ${ }^{24}$.

While some brain abnormalities observed in individuals with autism may reflect a potential role of oxygen deprivation during development, this possibility requires further examination. Hypoxia has also been shown to increase dopaminergic activity, and there is evidence for dopamine over activation in autism ${ }^{24}$.

Severe Hyperemesis was found not to be significantly associated with $11.5 \%$ in cases and $45.5 \%$ in controls (OR: 1.22 [95\% Cl: 0.35-4.2] $\mathrm{P}=0.75$ ). The positive relationship between nausea/vomiting and autism was only significant among prospective studies $(R R=1.48$, $95 \% \mathrm{Cl} 1.03$ to 2.14$)^{15}$. In fact, the meta-analysis restricted to the three retrospective studies that examined nausea/ vomiting in relation to autism suggested a protective association ( $\mathrm{RR}=0.55,95 \% \mathrm{Cl} 0.31$ to 0.98$)^{15}$.

Neonatal jaundice is found in $21.2 \%$ of the cases and $7.7 \%$ of controls. Neonatal complications including apnea and jaundice were extremely rare in similar research control group but much more common in case group, consistent with the findings of Maimburg et al. that an almost fourfold increased risk for infantile autism was observed in newborns exposed to hyperbilirubinaemia ${ }^{25}$.

\section{CONCLUSION}

In this study, our findings support various factors associated with ASD, nevertheless many of our findings does not show significant association. Since, not many studies have been conducted in Nepal for autism, additional studies are necessary to confirm our results, and public health measures could be taken to avoid modifiable risk factors.

\section{ACKNOWLEDGEMENT}

We are thankful to Autism Care Nepal Society (A National Centre for Autism), who provided with their insights and graciously supported our research. We are also thankful to Dr. Susant Gurung, Dr. Bidhan Raj Paudel, Dr. Prajwal KC, Dr. Pratik Pokharel, Dr. Anuja Khanal, Dr. Apurwa Prasad, Dr. Amrit Pokharel, Dr. Ujjwal Bhattarai and Dr. Sunil Pathak for their invaluable aid in data collection and remarkable expertise in expanding our scope in data from outside Kathmandu as well. 


\section{REFERENCES}

1. Zhang X, Lv C-C, Tian J, Miao R-J, Xi W, Hertz-Picciotto I, et al. Prenatal and perinatal risk factors for autism in China. Journal of autism and developmental disorders. 2010;40(11):1311-21.

2. Organization $\mathrm{WH}$. The ICD-10 classification of mental and behavioural disorders: diagnostic criteria for research[Internet]. 1993. Available from: http://www.who.int/classifications/icd/en/ GRNBOOK.pdf

3. Grether JK, Anderson MC, Croen LA, Smith D, Windham GC. Risk of autism and increasing maternal and paternal age in a large north American population. American Journal of Epidemiology. 2009 Nov;170(9):1118-26.

4. Christensen DL, Baio J, Braun KV, Bilder D, Charles J, Constantino J, et al. Prevalence and Characteristics of Autism Spectrum Disorder Among Children Aged 8 Years - Autism and Developmental Disabilities Monitoring Network, 11 Sites, United States, 2012. CDC Morbidity and Mortality Weekly Report (MMWR) Surveill Summ. 2016;65(No.SS-3):1-23. doi: http://dx.doi.org/10.15585/mmwr.ss6503a1.

5. Kim YS, Leventhal BL, Koh Y-J, Fombonne E, Laska $\mathrm{E}$, Lim E-C, et al. Prevalence of autism spectrum disorders in a total population sample. American Journal of Psychiatry. 2011;168(9):904-12.

6. Krishnamurthy V. A clinical experience of autism in India. Journal of Developmental \& Behavioral Pediatrics. 2008;29(4):331-3.

7. Daley TC, Sigman MD. Diagnostic conceptualization of autism among Indian psychiatrists, psychologists, and pediatricians. Journal of Autism and Developmental disorders. 2002;32(1):13-23.

8. Lauritsen MB, Pedersen CB, Mortensen PB. Effects of familial risk factors and place of birth on the risk of autism: a nationwide register based study. Journal of Child Psychology and Psychiatry. 2005;46(9):96371.

9. Reichenberg A, Gross R, Weiser M, Bresnahan M, Silverman J, Harlap $S$, et al. Advancing paternal age and autism. Archives of general psychiatry. 2006;63(9):1026-32.

10. Croen LA, Najjar DV, Fireman B, Grether JK. Maternal and paternal age and risk of autism spectrum disorders. Archives of pediatrics \& adolescent medicine. 2007;161(4):334-40.

11. Durkin MS, Maenner MJ, Newschaffer CJ, Lee L-C, Cunniff CM, Daniels JL, et al. Advanced parental age and the risk of autism spectrum disorder. American Journal of Epidemiology. 2008;168(11):1268-76.
12. King MD, Fountain C, Dakhlallah D, Bearman PS. Estimated autism risk and older reproductive age. American journal of public health. 2009;99(9):16739.

13. Mamidala MP, Kalikiri MK, Praveen Kumar PT, Rajesh $\mathrm{N}$, Vallamkonda OR, Rajesh V. Consanguinity in India and its association with autism spectrum disorder. Autism Research. 2015;8(2):224-8.

14. Bilder D, Pinborough-Zimmerman J, Miller J, McMahon W. Prenatal, perinatal, and neonatal factors associated with autism spectrum disorders. Pediatrics. 2009;123(5):1293-300.

15. Gardener H, Spiegelman D, Buka SL. Prenatal risk factors for autism: comprehensive meta-analysis. The British Journal of Psychiatry. 2009;195(1):7-14.

16. Daley TC, Sigman MD. Diagnostic conceptualization of autism among Indian psychiatrists, psychologists, and pediatricians. Journal of Autism and Developmental disorders. 2002;32(1):13-23.

17. Piven J, Palmer $P$, Jacobi $D$, Childress $D$, Arndt $S$. Broader autism phenotype: evidence from a family history study of multiple-incidence autism families. American Journal of Psychiatry. 1997;154(2):185-90.

18. Kolevzon A, Gross R, Reichenberg A. Prenatal and perinatal risk factors for autism: a review and integration of findings. Archives of pediatrics \& adolescent medicine. 2007;161(4):326-33.

19. Hultman CM, Sparén $P$, Cnattingius S. Perinatal risk factors for infantile autism. Epidemiology. 2002;13(4):417-23.

20. Atladóttir HÓ, Henriksen TB, Schendel DE, Parner ET. Autism after infection, febrile episodes, and antibiotic use during pregnancy: an exploratory study. Pediatrics. 2012;130(6):e1447-e54.

21. Zerbo O, Qian Y, Yoshida C, Grether JK, Van de Water J, Croen LA. Maternal infection during pregnancy and autism spectrum disorders. Journal of autism and developmental disorders. 2015;45(12):4015-25.

22. Libbey JE, Sweeten TL, McMahon WM, Fujinami RS. Autistic disorder and viral infections. Journal of neurovirology. 2005;11(1):1-10.

23. Brimacombe $M$, Ming $X$, Lamendola M. Prenatal and birth complications in autism. Maternal and child health journal. 2007;11(1):73-9.

24. Gillberg C, Schaumann H, Gillberg I. Autism in immigrants: children born in Sweden to mothers born in Uganda. Journal of Intellectual Disability Research. 1995;39(2):141-4.

25. Maimburg RD, Væth $M$, Schendel DE, Bech BH, Olsen J, Thorsen P. Neonatal jaundice: a risk factor for infantile autism? Paediatric and perinatal epidemiology. 2008;22(6):562-8. 